\title{
TITLE:
}

\section{Water sorption kinetics of spaghetti at different temperatures}

$\operatorname{AUTHOR}(\mathrm{S}):$

Ogawa, T.; Kobayashi, T.; Adachi, S.

\section{CITATION:}

Ogawa, T....[et al]. Water sorption kinetics of spaghetti at different temperatures. Food and Bioproducts Processing 2011, 89(2): 135-141

ISSUE DATE:

2011-04

URL:

http://hdl.handle.net/2433/159726

\section{RIGHT:}

(C) 2010 The Institution of Chemical Engineers. Published by Elsevier B.V.; この論文は出版社版でありません。引用の際には出版社版をご確 認ご利用ください。; This is not the published version. Please cite only the published version. 


\title{
Water Sorption Kinetics of Spaghetti at Different Temperatures
}

\author{
Takenobu OGAWA, Takashi KOBAYASHI, Shuji ADACHI* \\ Division of Food Science and Biotechnology, Graduate School of Agriculture, \\ Kyoto University, Sakyo-ku, Kyoto, 606-8502, Japan \\ *Corresponding author. \\ E-mail address: adachi@kais.kyoto-u.ac.jp (S. Adachi).
}

\begin{abstract}
The water sorption kinetics of spaghetti was measured in the temperature range of $20-90^{\circ} \mathrm{C}$ to investigate the temperature dependencies of an equilibrium moisture content and an initial rate of water sorption. The dependencies indicated the mechanism of water sorption: the equilibrium moisture content is limited by the state of starch gelatinization and the initial rate of water sorption is governed by the water diffusion through the pores of the spaghetti regardless of the starch gelatinization. The empirical equations were proposed to predict the amount of loss of the spaghetti mass during water sorption which results in the quality loss of cooked spaghetti and the moisture content which affects the mechanical properties and an optimal immersion time. The equation of the moisture content, taking the effect of starch gelatinization into consideration, has the initial diameter of spaghetti, immersion time, and temperature of immersed water as parameters to predict under any conditions.
\end{abstract}

Keywords: Loss of spaghetti mass; Water sorption; Temperature dependence; Starch gelatinization; Water diffusion; Hydration

\section{Introduction}

Drying is one of the most common methods of food preservation and is applied to various foodstuffs. Water sorption is a process aimed at the restoration of the properties of dried foodstuffs. This process is complicated, because water sorption is a multifaceted mass transport process and is governed by several mechanisms of water imbibitions in pores (Sam Saguy et al., 2005). A quantitative understanding of the change in the moisture content of spaghetti at any temperature of the immersed water is necessary to know the mechanical properties and the optimal immersion time of spaghetti (Chillo et al., 2008, 2009; Cuq et al., 2003).

Typically, equations to describe the water sorption kinetics can be characterized by two approaches: theoretical and empirical (García-Pascual et al., 2006). The theoretical equations are based on the Fick's first and second laws of diffusion, where the difference in the moisture content of spaghetti is considered to be a driving force (Bilbao-Sainz et al., 2005; 
García-Pascual et al., 2005, 2006; Sanjuán et al., 1999, 2004). Theoretical equations provide insights into the mechanistic relevance of an observed phenomenon (Sam Saguy et al., 2005). However, they are not convenient for practical purposes due to their complexity (Maskan, 2002; Cunningham et al., 2007): in addition to water diffusion, starch crystalline domains melting, macromolecular matrix relaxation, and "residual deformation" release also occur during water sorption (Del Nobile et al., 2003). On the other hand, the development of empirical equations requires considerably less effort. Therefore, empirical equations can be useful tools for the prediction and optimization of the water sorption kinetics (Djomdi and Ndjouenkeu, 2007). Empirical or semi-empirical equations of 6 types are often utilized to describe the water sorption kinetics (Maskan, 2002). These include: the exponential equation (Misra and Brooker, 1980), Peleg's model (Peleg, 1988), 1st order kinetics (Chhinnan, 1984), Becker's model (Becker, 1960), the Weibull distribution function (Cunha et al., 1998), and the normalized Weibull distribution function (Marabi et al., 2003). In the empirical equations, the water sorption process is treated as a 'black box', varying specific input setup parameters, measuring output quantities and deriving the adequate correlations. Therefore, it is necessary to determine the coefficients of the equation by varying the specific input setup parameters in detail. The moisture content of the spaghetti at any immersion time can be well predicted using Peleg's model and the Weibull distribution function (Cunningham et al., 2007). However, the temperature dependence of water sorption kinetics does not seem to be properly characterized. In particular, the effect of the starch gelatinization on the characteristics of water sorption kinetics has not been revealed. In addition, the reported equations cannot apply to spaghetti of a different diameter, even if the material is identical to each other.

In this study, the effects of the temperature of the immersion water on the characteristics of water sorption kinetics, such as the equilibrium moisture content and the initial rate of water sorption, were investigated in detail. The temperature of the immersed water was varied from $20^{\circ} \mathrm{C}$ to $90^{\circ} \mathrm{C}$ for an extended time period $(4 \mathrm{~h})$ to systematically observe the phenomena during water sorption. On the basis of the observations, an equation, which is a function of the initial diameter of the spaghetti, immersion time, and temperature of the immersed water, was proposed to describe the moisture content under any conditions.

\section{Material and Methods}

\subsection{Material}

Spaghetti Ma.Ma (Nisshin Foods, Inc., Tokyo, Japan), purchased from a local supermarket, was used in all the experiments. The carbohydrate content of the spaghetti was $72 \mathrm{wt} \%$. The initial diameters of the spaghetti were $1.4 \mathrm{~mm}$ (lot No.T0913 L), $1.6 \mathrm{~mm}$ (lot No. T1332 N), and 1.8 mm (lot No. 10.11.26 DS).

\subsection{Water sorption}

Initial moisture contents of spaghetti based on dry solid, $X_{0}$, were determined by drying about $0.2 \mathrm{~g}$ of sample, the weight of which had been accurately measured, in a convection drying oven (DO-300FA, As One, Japan) at 
$105^{\circ} \mathrm{C}$ for 4 days. The measurement was repeated three times. Culture tubes containing about $50 \mathrm{~cm}^{3}$ of distilled water were equilibrated at $20,40,50,55,60,70,80$, or $90^{\circ} \mathrm{C}$ in an SD thermominder and Personal-11 water bath (Taitec, Saitama, Japan). A sample cut into 9-cm-long, the weight of which was about 0.20 $\mathrm{g}, 0.26 \mathrm{~g}$ and $0.33 \mathrm{~g}$ for the $1.4-\mathrm{mm}, 1.6-\mathrm{mm}$ and 1.8-mm spaghetti respectively, was immersed into a tube (About 15 tubes were prepared under a specific condition). At a given time, the sample was removed from the tube, immediately blotted to remove any superficial water, and weighed, $W_{0}$. The samples were dried in the convection drying oven at $105^{\circ} \mathrm{C}$ for 4 days, and weighed, $W_{1}$.

\subsection{Volume measurement}

After the water sorption for a given period, the sample was immersed in a burette containing hexane $\left(25^{\circ} \mathrm{C}\right)$, and the sample volume was measured from the increase in the volume in the burette, assuming that a penetration of hexane into the spaghetti can be ignored. The samples were then dried in the convection drying oven at $105^{\circ} \mathrm{C}$ for 4 days, and weighed.

\subsection{Thermal analysis}

The gelatinization of spaghetti samples was measured by differential scanning calorimetry (DSC-50, Shimadzu, Kyoto, Japan). The sample was ground into a fine powder by using a pestle and mortar. The ground sample was accurately weighed $(1.5 \mathrm{mg})$ using a thermogravimetric analyzer (TGA-50, Shimadzu) and moistened with distilled water at a weight ratio of dry sample to water of around 1:6.5. The sample was sealed into an aluminum cell (seal cell 201-53090, Shimadzu) using a SSC-30 sealer crimper (Shimadzu). The cell was placed in a DSC pan with another cell in which the same amount of distilled water was sealed as a reference. The samples were heated in the DSC at $5^{\circ} \mathrm{C} / \mathrm{min}$ from 20 to $120^{\circ} \mathrm{C}$. The start $\left(T_{\mathrm{s}}\right)$, peak $\left(T_{\mathrm{p}}\right)$, and conclusion $\left(T_{\mathrm{c}}\right)$ temperatures for an endothermic peak were computed using analysis software supplied with the instrument. Each experiment was carried out in duplicate.

\subsection{Pore analysis}

\subsubsection{Pore-size distribution}

The pore-size distribution of spaghetti was analyzed by mercury intrusion porosimetry (Autopore 9520, Shimadzu) applying a pressure of up to $414 \mathrm{MPa}$. The pore diameter was calculated according to the Washburn equation (Washburn, 1921):

$P_{\mathrm{m}}=-4 \gamma \cos \theta / d_{\mathrm{c}}$

where $P_{\mathrm{m}}$ is the pressure $\left(\mathrm{N} \cdot \mathrm{m}^{-2}\right), \gamma$ is the surface tension of the mercury $\left(\mathrm{N} \cdot \mathrm{m}^{-1}\right), \theta$ is the contact angle between mercury and the sample, and $d_{\mathrm{c}}$ is the diameter of the capillary $(\mathrm{m})$. The surface tension of the mercury of $4.85 \times 10^{-1} \mathrm{~N} \cdot \mathrm{m}^{-1}$ and the contact angle of $130^{\circ}$ were used to calculate the pore size from the pressure measurement. The volume of mercury intruded at the maximum pressure was considered to be the total porosity. A sample of approximately $3 \mathrm{~g}$ was kept under vacuum at room temperature for $15 \mathrm{~h}$ for intrusion. An initial pressure was $7 \mathrm{kPa}$. The measurement was carried out in duplicate.

\subsubsection{Atomic force microscopy}


The surface of spaghetti was observed by a SPM-9500 atomic force microscope (AFM) (Shimadzu) with a silicon nitride triangular cantilever with a sharpened pyramidal tip (OMCL-TR800PSA-1, Olympus, Tokyo, Japan) having a nominal spring constant of $0.15 \mathrm{~N} / \mathrm{m}$. The imaging was performed in the constant contact force mode with a nominal imaging force of $16 \mathrm{nN}$. The scan area was $25 \mu \mathrm{m}^{2}$ with a scan frequency at $1.0 \mathrm{~Hz}$. The image was modified using the analysis software installed in the instrument.

\subsection{Statistical analyst}

The coefficients of the nonlinear regression between the observed and calculated values were determined using Solver in Microsoft Office Excel $2007^{\circledR}$. An accidental error of the coefficient was evaluated with a confidence level of $95 \%(P<0.05)$ by linearization (Miller and Miller, 1988). The good fit of the model was evaluated on the basis of the coefficient of the determination $\left(R^{2}\right)$ and the root-mean-square deviation (RMSD). The RMSD is defined as (Sopade et al., 1992)

$\mathrm{RMSD}=\frac{1}{n} \sqrt{\sum_{i=1}^{n}\left(X_{t}-X_{\mathrm{pi}}\right)^{2}}$

where $n$ is the number of experimental points, $X_{t}$ is the experimental moisture content, and $X_{\mathrm{pi}}$ is the predicted moisture content.

\section{Results and Discussion}

\subsection{Loss of spaghetti mass}

The spaghetti components leak into the immersed water during water sorption, resulting

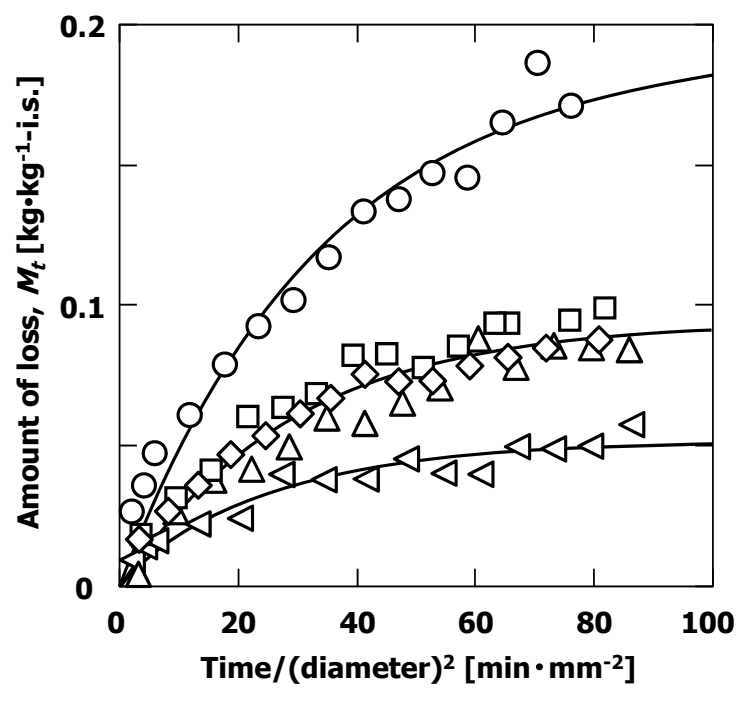

Figure 1 - Amount of loss of the spaghetti mass during water sorption at $90^{\circ} \mathrm{C}$ for the spaghettis with initial diameters of $1.6 \mathrm{~mm}(\bigcirc)$, at $50^{\circ} \mathrm{C}$ for the spaghettis with initial diameters of $1.4 \mathrm{~mm}$ $(\triangle), 1.6 \mathrm{~mm}(\square), 1.8 \mathrm{~mm}(\diamond)$, and at $20^{\circ} \mathrm{C}$ for the spaghettis with initial diameters of $1.6 \mathrm{~mm}$ $(\triangleleft)$. The amount of loss was expressed as $\mathrm{kg} \cdot \mathrm{kg}$ ${ }^{-1}$-initial mass (i.s.).

in the loss of its mass. The amount of the loss of spaghetti mass is generally significant, although a small amount of loss is preferred for a high quality of cooked spaghetti (Del Nobile et al., 2005). However, no correction was made for the loss in previous studies focused on the modeling of the moisture content. Figure 1 shows the relationship between the amount of the loss of spaghetti mass (initial solid (i.s.) basis), $M_{t}$, and the quotient of time by square of the diameter, $t \cdot d^{-2}$, where $d$ is the initial diameter of the spaghetti (m) at 20,50 , and $90^{\circ} \mathrm{C}$. The $M_{t}$ value was greater at the longer immersion time and at the higher temperature of the immersed water. The $M_{t}$ value reached approximately 0.2 $\mathrm{kg} \cdot \mathrm{kg}^{-1}$-i.s., which corresponded to approximately $20 \%$ of the spaghetti mass. The optimal "boiled condition" for dried spaghetti, called al dente, is cooked so as to be firm but not hard. The $M_{t}$ value at al dente, which was 
attained around $7 \mathrm{~min}$ for $1.6 \mathrm{~mm}$ diameter spaghetti in Fig. 1, was about $0.032 \mathrm{~kg}^{-k^{-1}}$-i.s. The moisture content at the early stage of water sorption, such as the condition of al dente, was only slightly affected by the loss. On the other hand, the effect of the loss on the moisture content at the latter stage became significant. Therefore, the loss should be considered to characterize the water sorption process.

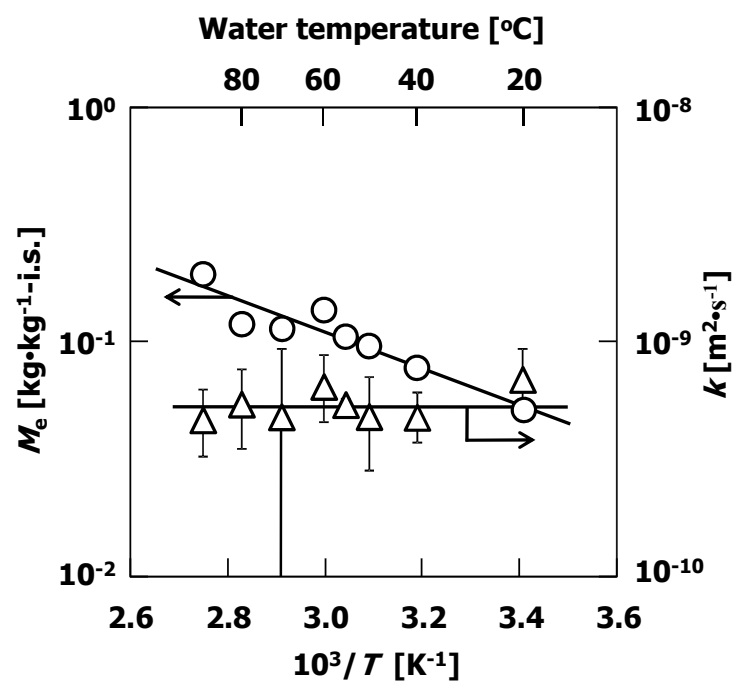

Figure 2 - Temperature dependencies of the equilibrium amount of loss $M_{\mathrm{e}}(\mathrm{O})$ and the rate constant $k(\triangle)$.

The plots of $M_{t}$ vs. $t \cdot d^{-2}$ for the spaghettis of 3 different diameters $(1.4,1.6$, and $1.8 \mathrm{~mm})$ at $50^{\circ} \mathrm{C}$ lay on a curve (Fig. 1). This fact indicated that the amount of loss of the spaghetti mass depends on the surface area of the spaghetti because the square of the diameter is proportional to the surface area. The equation (3) could express the observed amount of loss during water sorption as a function of time.

$$
M_{t}=M_{\mathrm{e}}\left[1-\exp \left(-k t / d^{2}\right)\right]
$$

where $M_{\mathrm{e}}$ is the equilibrium amount of the loss of spaghetti mass $\left(\mathrm{kg} \cdot \mathrm{kg}^{-1}-\right.$ i.s. $)$ and $k$ is the rate constant $\left(\mathrm{m}^{2} \cdot \mathrm{s}^{-1}\right)$. The maximum value of RMSD for the observed and calculated $M_{t}$ values was



Figure 3 - Changes in the moisture content at $50^{\circ} \mathrm{C}$ (closed symbols) and $80^{\circ} \mathrm{C}$ (open symbols) for the spaghettis with initial diameters of 1.4 $\mathrm{mm}(\triangle),(\boldsymbol{\Delta}), 1.6 \mathrm{~mm}(\square),(\boldsymbol{\square})$, and $1.8 \mathrm{~mm}$ $(\diamond),(\diamond)$

0.450, which demonstrates the suitability of Eq. (3) for describing the experimental loss of the spaghetti mass. Figure 2 shows the temperature dependencies of the $M_{\mathrm{e}}$ and $k$ values. The $k$ value was not affected by temperature, but the $M_{\mathrm{e}}$ value became large in reverse proportion to the absolute temperature. This result suggested that the leaking of spaghetti components into the immersed water during water sorption is a mechanical change such as exfoliation, not the chemical or physical changes such as the hydrogen bond breaking, diffusion, or absorption.

\subsection{Water sorption at various temperatures}

Figure 3 shows the relationship between the moisture content, $X_{t}$, and the quotient of time by square of the diameter, $t \cdot d^{-2}$,for the $1.4,1.6$, and $1.8 \mathrm{~mm}$ diameter spaghettis at 50 and $80^{\circ} \mathrm{C}$. The moisture content based on the net mass of spaghetti, $X_{t}$, was calculated by Eq. (4).

$X_{t}=\left(W_{0}-W_{1}\right) / W_{1}$ 


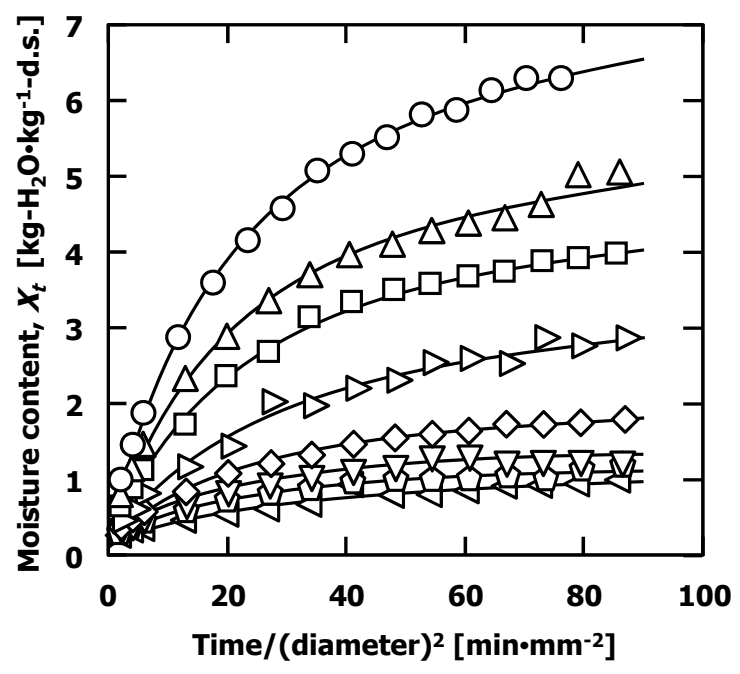

Figure 4 - Water sorption of spaghetti at $90^{\circ} \mathrm{C}$ $(\bigcirc), 80^{\circ} \mathrm{C}(\triangle), 70^{\circ} \mathrm{C}(\square), 60^{\circ} \mathrm{C}(\triangleright), 55^{\circ} \mathrm{C}(\diamond)$, $50^{\circ} \mathrm{C}(\nabla), 40^{\circ} \mathrm{C}(\triangle)$, and $20^{\circ} \mathrm{C}(\varangle)$. The spaghetti with an initial diameter of $1.6 \mathrm{~mm}$ was used. The water content $X_{t}$ was expressed as kg-water sorbed per dry solid (d.s.).

The $X_{t}$ values were larger at a higher temperature. The plots of $X_{t}$ vs. $t \cdot d^{-2}$ for the spaghettis of 3 different diameters lay on a curve at any temperature. This fact indicated that the water sorption of spaghetti is governed mainly by the water diffusion.

The hyperbolic equation has been applied to describe the moisture content of spaghetti as a function of time $t$ (Cunningham et al., 2007; García-Pascual et al., 2005, 2006). In this study, we applied the equation of hyperbolic type (Eq. (5)) to describe the $X_{t}$ value using the $t^{*} d^{-2}$ as an independent variable instead of time $t$.

$X_{t}=\frac{a \times\left(t / d^{2}\right)}{b+\left(t / d^{2}\right)}+X_{0}$

where $a\left(\mathrm{~kg}^{-} \mathrm{H}_{2} \mathrm{O} \cdot \mathrm{kg}^{-1}\right.$-d.s. $)$ and $b\left(\mathrm{~s} \cdot \mathrm{m}^{-2}\right)$ are constants. Figure 4 illustrates the water sorption process at $20-90^{\circ} \mathrm{C}$. The solid curves were calculated using the estimated $a$ and $b$ values. The maximum value of RMSD for the observed and calculated $X_{t}$ values was 0.030 , which demonstrates the appropriateness of Eq. (5) for describing the experimental water sorption char-

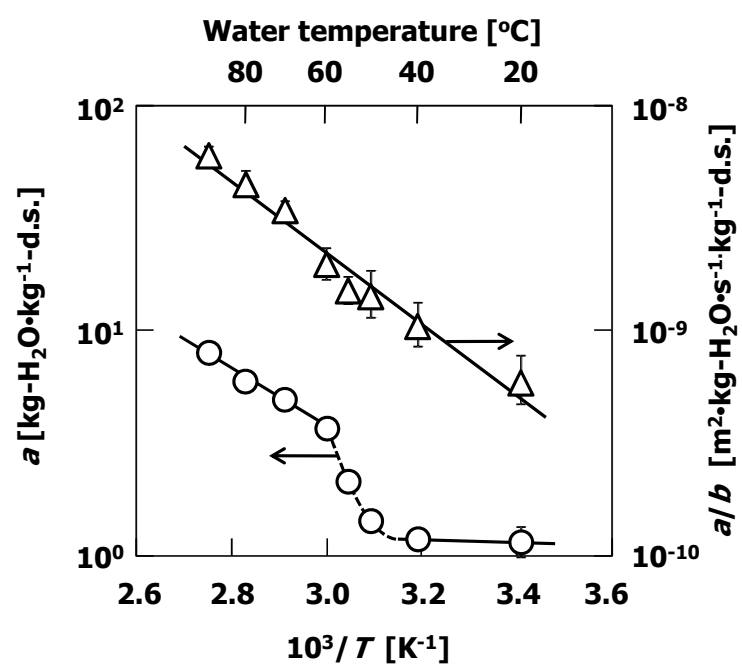

Figure 5 - Temperature dependencies of the equilibrium moisture content $a(\mathrm{O})$ and the initial rate of water sorption $a / b(\triangle)$. The $a$ and $a / b$ value were determined at the confidence level of $95 \%$.

acteristics of spaghetti.

The constants, $a$ and $b$, were estimated to best-fit the calculated $X_{t}$ values to the experimental ones using the Solver in Microsoft Excel ${ }^{\circledR}$. The solid curves in Figs. 3 and 4 were drawn using the estimated $a$ and $b$ values.

\subsection{Equilibrium moisture content}

The equilibrium moisture content at $t=\infty$, $X_{\mathrm{e}}$, is given by Eq. (6).

$X_{\mathrm{e}}=\lim _{t \rightarrow \infty} X_{t}=a+X_{0}$

The equilibrium moisture content, $X_{\mathrm{e}}$, can be approximated by $a$ because the $X_{0}$ value is much less than the $a$ value. The temperature dependence of the $a$ value was analyzed using Eq. (7) based on van't Hoff's equation.

$\frac{d \ln a}{d(1 / T)}=-\frac{\Delta H}{R}$

where $\Delta H$ is a change in the enthalpy of the water sorption $\left(\mathrm{J} \cdot \mathrm{mol}^{-1}\right)$ and $R$ is the gas constant $\left(8.314 \mathrm{~J} \cdot \mathrm{mol}^{-1} \cdot \mathrm{K}^{-1}\right)$. The $a$ values were plotted 
versus the reciprocal of the absolute temperature (Fig. 5). The plots would be separated in 3 regions: high temperature, transition, and low temperature regions. The gelatinization temperatures, $T_{\mathrm{s}}\left(45.3^{\circ} \mathrm{C}\right), \quad T_{\mathrm{p}}\left(60.5^{\circ} \mathrm{C}\right), \quad$ and $T_{\mathrm{c}}\left(69.8^{\circ} \mathrm{C}\right)$, were obtained from the analysis of the DSC curve. The start and end temperatures of the transition region were $45^{\circ} \mathrm{C}$ and $60^{\circ} \mathrm{C}$, respectively. These results indicated that starch in spaghetti was not gelatinized in the low temperature region but completely gelatinized in the high temperature region. In the low temperature region, the $\Delta H$ value was 1.44 $\mathrm{kJ} \cdot \mathrm{mol}^{-1}$ (the value of $a$ at $T=\infty$ was 2.06 $\mathrm{kg}-\mathrm{H}_{2} \mathrm{O} \cdot \mathrm{kg}^{-1}$-d.s.) and the $a$ value was small. On the other hand, in the high temperature region, the $\Delta H$ value was $25.1 \mathrm{~kJ} \cdot \mathrm{mol}^{-1}\left(R^{2}>0.992\right)$ (the value of $a$ at $T=\infty$ was $3.16 \times 10^{-4}$ $\mathrm{kg}-\mathrm{H}_{2} \mathrm{O} \cdot \mathrm{kg}^{-1}$-d.s.) and the $a$ value was large.

The moisture content significantly increases with the starch gelatinization due to the high carbohydrate content of the spaghetti (72\%) (Nagao et al., 2003). Starch sorbs water reversibly, and the water is mainly held in an amorphous region of the starch at temperatures lower than the gelatinization temperature (i.e., in the low temperature region in Fig. 5) (Nagao et al., 2003). That is, the water would interact with the spaghetti components by a weak force such as van der Waals' force. The reversible interaction with the weak attractive force resulted in a small $\Delta H$ value and water retention in the pores resulted in a small $a$ value in the low temperature region. On the other hand, the heating of the starch with water at temperatures higher than the gelatinization temperature (i.e., in the high temperature region in Fig. 5) causes an irreversible change in both the amorphous and crystalline regions (Nagao et al., 2003;

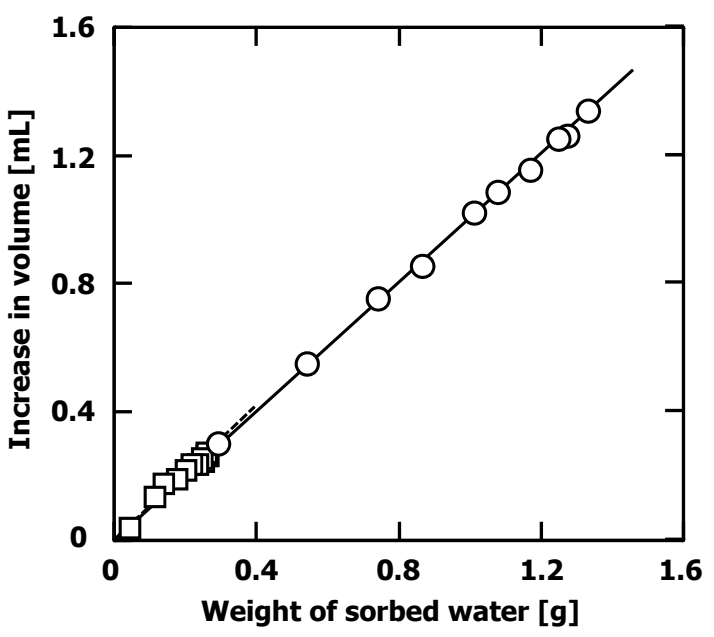

Figure 6 - Estimation of the apparent specific volumes of water in spaghetti at $80^{\circ} \mathrm{C}(-\mathrm{O}-)$ and $40^{\circ} \mathrm{C}$ (--- $\left.\square---\right)$. The spaghetti with an initial diameter of $1.8 \mathrm{~mm}$ was used.

Fuwa et al., 2003) to break intra- and/or intermolecular hydrogen bonds of amylopectin and amylose, which both maintain the structure of starch. The sorbed water would form a hydrogen bond with the hydroxyl group of the exposed sugar residues. The force of the hydrogen bond is much stronger than van der Waals'. The irreversible reaction with a strong adhesive force resulted in an extremely large $\Delta H$ value and the swelling by starch gelatinization (hydration) resulted in a large $a$ value in the high temperature region.

\subsection{Specific volume of water}

Figure 6 shows the relationship between the increase in the volume of the spaghetti and the weight of the sorbed water. The slope of the line gives the apparent specific volume of water in the spaghetti. The volumes were $1.02 \pm 1.5 \times 10^{-1}$ and $0.99 \pm 2.2 \times 10^{-2} \mathrm{~mL} \cdot \mathrm{g}^{-1}(P<0.05)$ at $40^{\circ} \mathrm{C}$ $\left(<T_{\mathrm{s}}\right)$ and $80^{\circ} \mathrm{C}\left(>T_{\mathrm{p}}\right)$, respectively. Although the difference in the specific volume was not significant, the specific volume at $40^{\circ} \mathrm{C}$ was 
larger than that at $80^{\circ} \mathrm{C}$. Sorbed water would fill the pores of the spaghetti at temperatures lower than the gelatinization temperature, but the water would also penetrate into the gelatinized region of the spaghetti at higher temperatures. Water which penetrated into the region seemed to result in a smaller volume. However, further studies are required to elucidate the reason for the difference in the specific volume of water in spaghetti.

\subsection{Initial rate of water sorption}

The initial rate of water sorption, $v_{0}$, which is a derivative of $X_{t}$ at $t=0$, is given by the $a / b$ value (Eq. (8)).

$v_{0}=d^{2} d X_{t} /\left.d t\right|_{t=0}=a / b$

The temperature dependence of the initial rate of water sorption is reported to be expressed by the Arrhenius equation Eq. (9) (Maskan, 2002).

$v_{0}=a / b=A_{0} \exp \left(-E_{\mathrm{a}} / R T\right)$

where $A_{0}$ is the frequency factor $\left(\mathrm{m}^{2} \cdot \mathrm{kg}-\mathrm{H}_{2} \mathrm{O} \cdot \mathrm{s}^{-1} \cdot \mathrm{kg}^{-1}\right.$-d.s. $)$, and $E_{\mathrm{a}}$ is the activation energy $\left(\mathrm{J} \cdot \mathrm{mol}^{-1}\right)$. Figure 5 shows the relationship between the initial rate of water sorption and the reciprocal of the absolute temperature. The plots lie on a line $\left(R^{2}=0.969\right)$ in the entire temperature range. The $E_{\mathrm{a}}$ and $A_{0}$ values were estimated to be $30.5 \mathrm{~kJ} \cdot \mathrm{mol}^{-1}$ and $1.36 \times 10^{-4}$ $\mathrm{m}^{2} \cdot \mathrm{kg}-\mathrm{H}_{2} \mathrm{O} \cdot \mathrm{s}^{-1} \cdot \mathrm{kg}^{-1}$-d.s., respectively.

The temperature dependence of the $a$ value in the high temperature region was different from that in the low temperature region, being significantly affected by the starch gelatinization. On the other hand, the temperature dependence of $a / b$ could be expressed by Eq. (9) in the entire

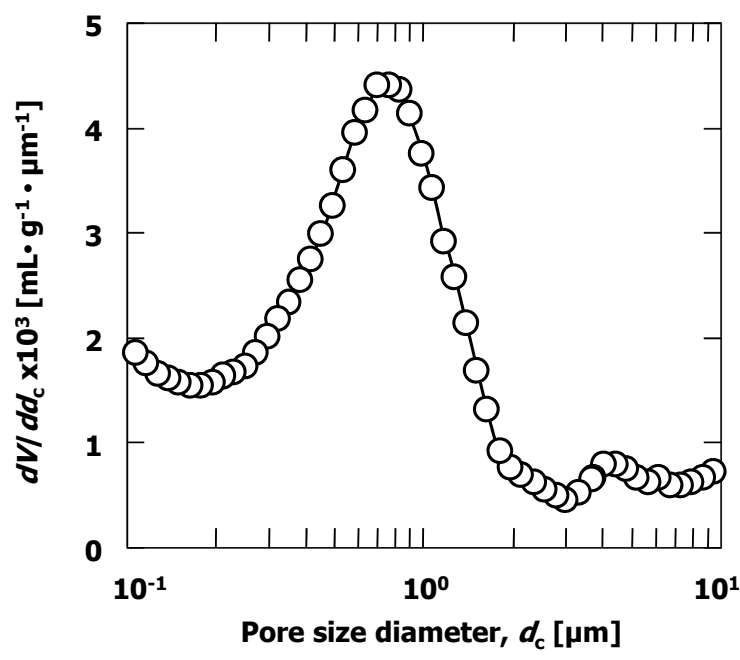

Figure 7 - The pore-size distribution of spaghetti by the mercury intrusion porosimetry, where $V$ is the cumulative intrusion of mercury. The median and mode radii were 0.66 and 0.75 $\mu \mathrm{m}$, respectively.

temperature range. This result indicated that the initial rate of water sorption was not affected by the starch gelatinization.

Figure 7 shows the pore-size distribution of spaghetti by mercury intrusion porosimetry, and Fig. 8 shows the AFM image of the spaghetti surface. These results showed that spaghetti was a porous material and the pores of around 0.7 $\mu \mathrm{m}$ were distributed on the surface. The water diffused from the surface to the center of the spaghetti through the pores would form the hy-



Figure 8 - AFM image of the spaghetti surface. The $x$ and $y$ scan sizes were both $5 \mu \mathrm{m}$. The $z$ $\max$ was $308.90 \mathrm{~nm}$. 
drogen bond with a hydroxyl group at temperatures higher than the gelatinization temperature. The hydration rate is, however, assumed to be much faster than the diffusion rate of water. Thus, the rate of water sorption was governed by the diffusion rate of water, although the equilibrium moisture content was limited by the state of the starch gelatinization. Therefore, the initial rate of water sorption was not slightly affected by the starch gelatinization.

The initial rate of water sorption has a close relationship to the optimal immersion time because al dente is the state at the early stage of the water sorption. The initial rate of water sorption was significantly affected by the diffusion rate of water through the pores. Therefore, in order to shorten the immersion time, it would be necessary to enlarge the pores of spaghetti.

\section{Conclusion}

The loss of spaghetti mass should be considered to predict the moisture content of the spaghetti with a high accuracy. We proposed the equation to predict the amount of loss of spaghetti mass during water sorption which was proportional to the surface area of spaghetti. The leakage of spaghetti components into immersed water during water sorption was thought to be the mechanical change such as exfoliation. The equilibrium moisture content showed the temperature dependence of van't Hoff type separately at the temperatures higher than $T_{\mathrm{p}}$ and lower than $T_{\mathrm{s}}$. The initial rate of water sorption showed a temperature dependence of the Arrhenius type in the temperature range of $20-90^{\circ} \mathrm{C}$. The rate of water sorption was governed by the water diffusion through the pores of the spaghetti, because the hydration rate seemed to be much faster than the diffusion rate of water. On the other hand, the equilibrium moisture content was limited by the state of starch gelatinization at any temperature. The empirical equation, the parameters of which were the diameter of spaghetti, immersion time, and temperature of the immersed water, was proposed to predict the moisture content, taking into consideration the effect of starch gelatinization.

\section{Nomenclatures}

\begin{tabular}{|c|c|}
\hline$a$ & constant number $\left(\mathrm{kg}-\mathrm{H}_{2} \mathrm{O} \cdot \mathrm{kg}^{-1}\right.$-d.s. $)$ \\
\hline$A_{0}$ & $\begin{array}{l}\text { frequency factor }\left(\mathrm{m}^{2} \cdot \mathrm{kg}-\mathrm{H}_{2} \mathrm{O} \cdot \mathrm{s}^{-1} \cdot \mathrm{kg}^{-1}-\right. \\
\text { d.s. })\end{array}$ \\
\hline$b$ & constant number $\left(\mathrm{s} \cdot \mathrm{m}^{-2}\right)$ \\
\hline$d$ & initial diameter of spaghetti (m) \\
\hline$d_{\mathrm{c}}$ & diameter of capillary (m) \\
\hline$E_{\mathrm{a}}$ & activation energy $\left(\mathrm{J} \cdot \mathrm{mol}^{-1}\right)$ \\
\hline$k$ & rate constant $\left(\mathrm{m}^{2} \cdot \mathrm{s}\right)$ \\
\hline$M_{\mathrm{e}}$ & $\begin{array}{l}\text { equilibrium loss of spaghetti mass } \\
\left(\mathrm{kg} \cdot \mathrm{kg}^{-1} \text {-i.s. }\right)\end{array}$ \\
\hline$M_{t}$ & $\begin{array}{l}\text { loss of spaghetti mass at time } t(\mathrm{~kg} \cdot \mathrm{kg} \\
\left.{ }^{-1} \text {-i.s. }\right)\end{array}$ \\
\hline$n$ & number of experimental points \\
\hline$P$ & $P$-value \\
\hline$P_{\mathrm{m}}$ & pressure $\left(\mathrm{N} \cdot \mathrm{m}^{-2}\right)$ \\
\hline$R$ & gas constant $\left(8.314 \mathrm{~kJ} \cdot \mathrm{mol}^{-1} \cdot \mathrm{K}^{-1}\right)$ \\
\hline$R^{2}$ & correlation coefficient \\
\hline$t$ & time (s) \\
\hline$T$ & absolute temperature $(\mathrm{K})$ \\
\hline$T_{\mathrm{c}}$ & conclusion temperature of gelatiniza \\
\hline & -tion $\left({ }^{\circ} \mathrm{C}\right)$ \\
\hline$T_{\mathrm{p}}$ & peak temperature of gelatinization $\left({ }^{\circ} \mathrm{C}\right)$ \\
\hline$T_{\mathrm{s}}$ & start temperature of gelatinization $\left({ }^{\circ} \mathrm{C}\right)$ \\
\hline$v_{0}$ & initial rate of water sorption $\left(\mathrm{m}^{2} \cdot \mathrm{kg}-\right.$ \\
\hline & $\mathrm{H}_{2} \mathrm{O} \cdot \mathrm{s}^{-1} \cdot \mathrm{kg}^{-1}$-d.s.) \\
\hline
\end{tabular}




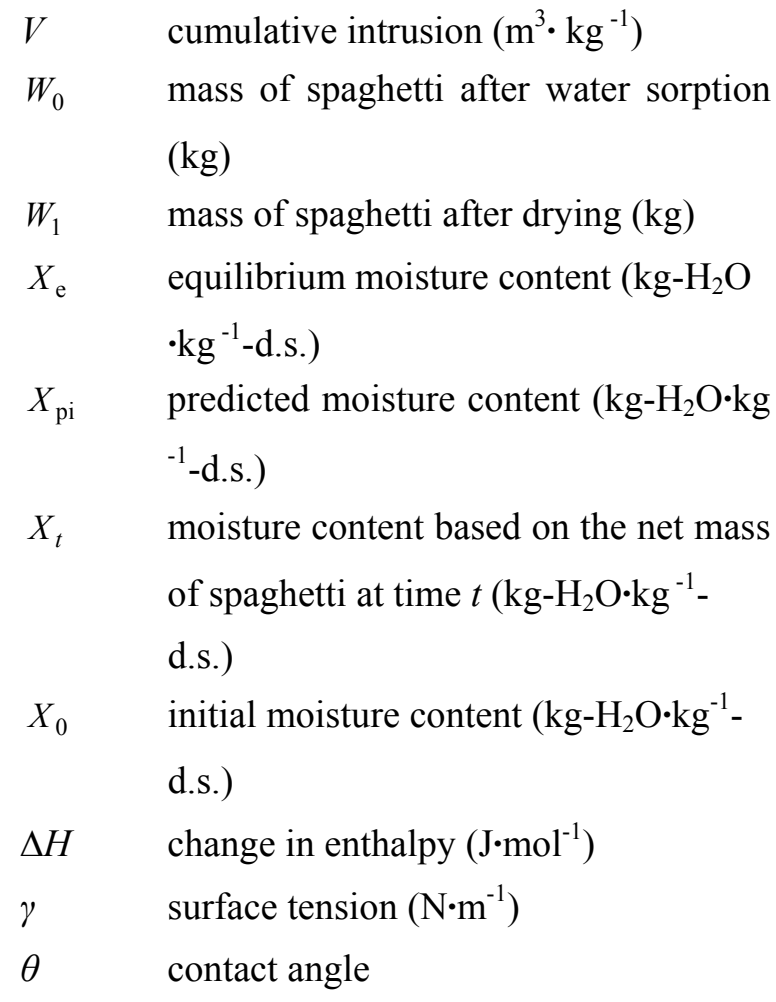

\section{Reference}

Becker, H.A., 1960, On the absorption of liquid water by the wheat kernel. Cereal Chem, 37:309-323.

Bilbao-Sáinz, C., Andrés, A. and Fito, P., 2005, Hydration kinetics of dried apple as affected by drying conditions. J Food Eng, 68(3):369-376.

Chhinnan, M.S., 1984, Evaluation of selected mathematical models for describing thin-layer drying of in-shell pecans. Transactions of the ASAE, 27(2):610-615.

Chillo, S., Iannetti, M., Civica, V., Suriano, N., Mastromatteo, M. and Del Nobile, M.A., 2009, A study of the relationship between the mechanical properties and the sensorial optimal cooking time of spaghetti. J Food Eng, 94(3-4):222-226.

Chillo, S., Laverse, J., Falcone, P.M., Protopapa, A. and Del Nobile, M.A., 2008, Influence of the addition of buckwheat flour and durum wheat bran on spaghetti quality. J Cereal Sci, 47(2):144-152.

Cunha, L.M., Oliveira, F.A.R. and Oliveira, J.C., 1998, Optimal experimental design for estimating the kinetic parameters of processes described by the Weibull probability distribution function. J Food Eng, 37(2):175-191.

Cunningham, S.E., McMinn, W.A.M., Magee, T.R.A. and Richardson, P.S., 2007, Modelling water absorption of pasta during soaking. J Food Eng, 82(4):600-607.

Cuq, B., Gonçalves, F., François Mas, J., Vareille, L. and Abecassis, J., 2003, Effects of moisture content and temperature of spaghetti on their mechanical properties. J Food Eng, 59(1):51-60.

Del Nobile, M.A., Buonocore, G.G., Panizza, A. and Gambacorta, G., 2003, Modeling the Spaghetti Hydration Kinetics During Cooking and Overcooking. J Food Sci, 68(4):1316-1323.

Del Nobile, M.A., Baiano, A., Conte, A. and Mocci, G., 2005, Influence of protein content on spaghetti cooking quality. J Cereal Sci, 41(3):347-356.

Djomdi, E. R. and Ndjouenkeu, R., 2007, Soaking behaviour and milky extraction performance of tiger nut (Cyperus esculentus) tubers. J Food Eng, 78(2):546-550.

Fuwa, H., Komaki, T., Hidukuri, S. and Kainuma, K., 2003, Handbook of Starch Science (in Japanese; Denpun Kagaku no Jiten) (1 ed.) (Asakura Shoten, Tokyo, Japan), pp. 554.

García-Pascual, P., Sanjuán, N., Bon, J., Carreres, J.E. and Mulet, A., 2005, Rehydration process of Boletus edulis mushroom: 
characteristics and modelling. J Sci Food Agric, 85(8):1397-1404.

García-Pascual, P., Sanjuán, N., Melis, R. and Mulet, A., 2006, Morchella esculenta (morel) rehydration process modelling. J Food Eng, 72(4):346-353.

Marabi, A., Livings, S., Jacobson, M. and Saguy, I.S., 2003, Normalized Weibull distribution for modeling rehydration of food particulates. Eur Food Res Technol, 217:311-318.

Maskan, M., 2002, Effect of processing on hydration kinetics of three wheat products of the same variety. J Food Eng, 52(4):337-341.

Miller, J.C. and Miller, J.N., 1988, Statistics for analytical chemistry (2nd ed.) (Ellis Horwood Limited, Great Britain).

Misra, M.K. and Brooker, D.B., 1980, Thin-layerdrying and rewetting equations for shelled yellow corn. Transactions of the ASAE, 23:1254-1260.

Nagao, S., Seko, H., Endo, S.,Uchida, M., Imai, T., Seguchi, M. and Shimada, J., 2003, Wheat Science (in Japanese; Komugi no Kagaku) (1 ed.) (Asakura Shoten, Tokyo, Japan).

Peleg, M., 1988, An empirical model for the description of moisture sorption curves. J Food Sci, 53(4):1216-1219.

Sam Saguy, I., Marabi, A. and Wallach, R., 2005, New approach to model rehydration of dry food particulates utilizing principles of liquid transport in porous media. Trends Food Sci Technol, 16(11):495-506.

Sanjuán, N., Bon, J., Clemente, G. and Mulet, A., 2004 , Changes in the quality of dehydrated broccoli florets during storage. J Food Eng, 62(1):15-21.
Sanjuán, N., Simal, S., Bon, J. and Mulet, A., 1999, Modelling of broccoli stems rehydration process. J Food Eng, 42(1):27-31.

Sopade, P.A., Ajisegiri, E.S. and Badau, M.H., 1992, The use of Peleg's equation to model water absorption in some cereal grains during soaking. J Food Eng, 15(4):269-283.

Washburn, E.W., 1921, Note on a Method of Determining the Distribution of Pore Sizes in a Porous Material. Proc Natl Acad Sci, 7(4):115-116.

\section{Acknowledgment}

This study was carried out during the course of a project of 'The Cereal Science Consortium by the Graduate School of Agriculture, Kyoto University and the Nisshin Seifun Group, Inc'. 